oropharyngeal saliva samples and serum antibody responses during infection by SARS-CoV-2: an observational cohort study. Lancet Infect Dis. 2020;20:565-74. https:/ / doi.org/10.1016/S1473-3099(20)30196-1

6. Jin Y, Wang M, Zuo Z, Fan C, Ye F, Cai Z, et al. Diagnostic value and dynamic variance of serum antibody in coronavirus disease 2019. Int J Infect Dis. 2020;94:49-52. https:/ / doi.org/10.1016/j.ijid.2020.03.065

7. Pan Y, Long L, Zhang D, Yuan T, Cui S, Yang P, et al. Potential false-negative nucleic acid testing results for severe acute respiratory syndrome coronavirus 2 from thermal inactivation of samples with low viral loads. Clin Chem. 2020;66:794-801. https://doi.org/10.1093/clinchem/hvaa091

8. Li D, Wang D, Dong J, Wang N, Huang H, Xu H, et al. False-negative results of real-time reverse-transcriptase polymerase chain reaction for severe acute respiratory syndrome coronavirus 2: role of deep-learning-based CT diagnosis and insights from two cases. Korean J Radiol. 2020;21:505-8. https:// doi.org/10.3348/kjr.2020.0146

9. Ong SWX, Tan YK, Chia PY, Lee TH, Ng OT, Wong MSY, et al. Air, surface environmental, and personal protective equipment contamination by severe acute respiratory syndrome coronavirus 2 (SARS-CoV-2) from a symptomatic patient. JAMA. 2020;323:1610. https://doi.org/10.1001/ jama.2020.3227

10. Heilongjiang Province People's Government. 51st press conference on the progress of joint prevention and control of the new coronavirus pneumonia epidemic in Heilongjiang Province; April 28, 2020 [in Chinese] [cited 2020 Jun 1]. http:/ / www.hlj.gov.cn/ftzb/system/ 2020/ 04/28/010925063.shtml

Address for correspondence: Dandan Xiang, Department of Infectious Diseases, Tongji Hospital, Tongji Medical College, Huazhong University of Science and Technology, 1095 Jiefang Avenue, Wuhan 430030, China; email: ddxiang2013@163.com

\section{Antibody Responses after Classroom Exposure to Teacher with Coronavirus Disease, March 2020}

\author{
Nicole E. Brown, ${ }^{1}$ Jonathan Bryant-Genevier, ${ }^{1}$ \\ Uptala Bandy, Carol A. Browning, Abby L. Berns, \\ Mary Dott, Michael Gosciminski, Sandra N. Lester, \\ Ruth Link-Gelles, Daniela N. Quilliam, James Sejvar, \\ Natalie J. Thornburg, Bernard J. Wolff, John Watson
}

DOI: https://doi.org/10.3201/eid2609.201802
Author affiliations: Centers for Disease Control and Prevention, Atlanta, Georgia, USA (N.E. Brown, J. Bryant-Genevier, M. Dott, S.N. Lester, R. Link-Gelles, J. Sejvar, N.J. Thornburg, B.J. Wolff, J. Watson); Rhode Island Department of Health, Providence, Rhode Island, USA (U. Bandy, C.A. Browning, A.L. Berns, M. Gosciminski, D.N. Quilliam); US Public Health Service Commissioned Corps, Rockville, Maryland, USA (M. Dott, R. Link-Gelles, J. Sejvar)

After returning from Europe to the United States, on March 1, 2020, a symptomatic teacher received positive test results for severe acute respiratory syndrome coronavirus 2. Of the 21 students exposed to the teacher in the classroom, serologic results suggested past infection for 2. Classroom contact may result in virus transmission.

Tn late February 2020, a teacher experienced headache, sore throat, myalgia, and fatigue while traveling in Europe, where community transmission of severe acute respiratory syndrome coronavirus 2 (SARS-CoV-2) was ongoing (1). After arriving back in the United States, the teacher returned to school February 24-27 while experiencing the same symptoms plus limited cough. An oropharyngeal swab sample collected on March 1 was positive for SARS-CoV-2 by reverse transcription PCR (cycle threshold values $\mathrm{N} 1=35.05, \mathrm{~N} 2=35.2 ;$ RNase $\mathrm{P}=23.58$ ). All students who attended classes with the infected teacher were instructed to quarantine themselves at home through March 12. After the quarantine period, we conducted a serologic survey to assess potential SARS-CoV-2 transmission in a classroom setting.

During February 24-27, the teacher taught 16 classes, all in the same room, each with $\leq 30$ students. Of the 16 classes, 10 were discussion-based, in which the teacher reported walking around the room and speaking directly with students (interactive classes). For the other 6 classes, the teacher sat mostly in 1 location and close interactions with students were limited (noninteractive classes). On March 10, we contacted 120 students (48 [40\%] enrolled in interactive classes, 72 [60\%] enrolled in noninteractive classes) whose only known exposure was through classroom contact with the teacher and invited them to participate in our serologic survey; 21 (18\%) students volunteered.

Median participant age was 17 years (range 5-18 years). Five (24\%) participants had interactive classroom contact; mean in-class time was 108 minutes. Sixteen $(76 \%)$ participants had noninteractive classroom contact only; mean in-class time was 50 minutes.

Participating students completed a questionnaire about symptoms experienced during the quarantine period and provided a blood specimen. On March 13,

${ }^{1}$ These first authors contributed equally to this article. 
whole blood (3-5 mL) was collected and serum was separated before samples were frozen at $-80^{\circ} \mathrm{C}$ for shipping. The Centers for Disease Control and Prevention tested the samples for antibodies by ELISA, as described previously (B. Freeman et al., unpub. data, https://www.biorxiv.org/content/10.1101/20 20.04.24.057323v2). We considered reciprocal titers of $\geq 400$ to be positive and reciprocal titers of $\geq 100$ but $<400$ to be indeterminate.

Of the 5 students with interactive classroom contact, results for 2 (students A and B) were suggestive of previous SARS-CoV-2 infection; results for student A were positive and for student $B$ indeterminate (Table). Students A and B were not in the classroom during the same period and sat in different locations in the classroom. Student A had a reciprocal titer of 400 and spent 135 minutes in interactive classes. Beginning February 26 , this student experienced intermittent myalgia, rhinorrhea, and cough for 9 days. Student B had a reciprocal titer of 100, spent 90 minutes in the interactive classroom, and reported no symptoms. The remaining 3 students (students C-E) had reciprocal titers of $<100$. Student $C$ spent 135 minutes in interactive classes and reported no symptoms. Students D and E each spent 90 minutes in interactive classes and reported limited symptoms. Student D reported subjective fever and headache lasting 1 day, and student E reported rhinorrhea lasting 1 day. Although no serologic evidence of previous infection was found for participants with noninteractive classroom contact only, 7 (44\%) reported symptoms. The most common symptoms among participants with noninteractive classroom contact were sore throat $(\mathrm{n}=3)$, headache $(\mathrm{n}=3)$, rhinorrhea $(\mathrm{n}=2)$, and myalgia $(\mathrm{n}=2)$.

Although SARS-CoV-2 transmission from symptomatic persons to close contacts has been well established, risks associated with classroom contact are not well known. The positive results for student A suggest past infection with SARS-CoV-2. The meaning of the indeterminate result for student $\mathrm{B}$ is less clear in this context, but this result may be suggestive of past infection. We do not know whether results from student A or B are indicative of immunity to SARS-CoV-2 infection. The symptoms reported by both students are consistent with those reported by children and adolescents with mildly symptomatic and asymptomatic coronavirus disease $(2,3)$.

This survey is subject to limitations. First, we based the definition of interactive classroom contact on reported usual behavior by the teacher; however, variability of contact for each participant was not defined. Second, reported symptoms might have been affected by students' expectation of the survey's intent, leading to social desirability bias. Third, because of low participation, the results may not be generalizable to all students who had contact with the teacher. Fourth, among students who chose to participate, participation might have been influenced by their perceived risk or symptoms experienced during the quarantine period, leading to selection bias. Fifth, potential infections may not have been detected because blood collection $\approx 14$ days after exposure may have been too soon for development of SARS-CoV-2 antibodies. Last, the only known exposure for participating students was the infected teacher; however, students could have been exposed by unrecognized community transmission. The risk for transmission from mildly symptomatic or asymptomatic persons is not well known.

Widespread school closures have mostly eliminated the risk for classroom transmission of SARSCoV-2. However, these results suggest that classroom interaction between an infected teacher and students might result in virus transmission.

\section{Acknowledgments}

We thank the principal and staff at the participating school, staff who conducted interviews and collected blood, laboratory staff who conducted testing, and Booker T. Daniels.

\section{About the Author}

Dr. Brown is an Epidemic Intelligence Service Officer in the Meningitis and Vaccine Preventable Diseases Branch, Division of Bacterial Diseases, National Center for Immunization and Respiratory Diseases, Centers for Disease Control and Prevention, in Atlanta, GA, USA. Her research interests include the epidemiology, control, and prevention of infectious diseases.

\begin{tabular}{|c|c|c|c|c|}
\hline Student & $\begin{array}{l}\text { ELISA result } \\
\text { reciprocal titer }\end{array}$ & $\begin{array}{l}\text { ELISA result } \\
\text { interpretation }\end{array}$ & $\begin{array}{l}\text { Minutes spent in } \\
\text { interactive classroom }\end{array}$ & Symptoms (duration, d) \\
\hline A & 400 & Positive & 135 & Myalgia (1), rhinorrhea (1), cough (3) \\
\hline $\mathrm{B}$ & 100 & Indeterminate & 90 & None \\
\hline $\mathrm{C}$ & $<100$ & Negative & 135 & None \\
\hline $\mathrm{D}$ & $<100$ & Negative & 90 & Subjective fever (1). headache (1) \\
\hline$E$ & $<100$ & Negative & 90 & Rhinorrhea (1) \\
\hline
\end{tabular}




\section{References}

1. Kinross P, Suetens C, Gomes Dias J, Alexakis L, Wijermans A, Colzani E, et al.; ECDC Public Health Emergency Team. Rapidly increasing cumulative incidence of coronavirus disease (COVID-19) in the European Union/European Economic Area and the United Kingdom, 1 January to 15 March 2020. Euro Surveill. 2020;25. https:/ / doi.org/ 10.2807/1560-7917.ES.2020.25.11.2000285

2. CDC COVID-19 Response Team. Coronavirus disease 2019 in children - United States, February 12-April 2, 2020. MMWR Morb Mortal Wkly Rep. 2020;69;422-426 [Epub ahead of print]. http://doi.org/10.15585/mmwr.mm6914e4

3. Castagnoli R, Votto M, Licari A, Brambilla I, Bruno R, Perlini $S$, et al. Severe acute respiratory syndrome coronavirus 2 (SARS-CoV-2) infection in children and adolescents: a systematic review. JAMA Pediatr. 2020 Apr 22 [Epub ahead of print]. https://doi.org/10.1001/ jamapediatrics.2020.1467

Address for correspondence: Nicole E. Brown, Centers for Disease Control and Prevention, 1600 Clifton Rd NE, Mailstop H24-6, Atlanta, GA 30329-4027, USA; email: lvx6@cdc.gov

\section{Severe Acute Respiratory Syndrome Coronavirus 2 among Asymptomatic Workers Screened for Work Resumption, China}

\author{
Xiaoyu Han, ${ }^{1}$ Xiong Wei, ${ }^{1}$ Osamah Alwalid, ${ }^{1}$ \\ Yukun Cao, Yumin Li, Li Wang, ${ }^{2}$ Heshui Shi ${ }^{2}$
}

Author affiliations: Union Hospital, Tongji Medical College, Wuhan, China (X. Han, O. Alwalid, Y. Cao, Y. Li, H. Shi); Hubei Province Key Laboratory of Molecular Imaging, Wuhan (X. Han, O. Alwalid, Y. Li, H. Shi); Wuhan Pingan Healthcare Diagnostic Center, Wuhan (X. Wei, L. Wang)

DOI: https://doi.org/10.3201/eid2609.201848

After the outbreak in Wuhan, China, we assessed 29,299 workers screened for severe acute respiratory syndrome coronavirus 2 by reverse transcription PCR. We noted $18(0.061 \%)$ cases of asymptomatic infection; 13 turned negative within 8.0 days, and 41 close contacts tested negative. Among 6 contacts who had serologic tests, none were positive.

${ }^{1}$ These first authors contributed equally to this article.

${ }^{2}$ These senior authors contributed equally to this article.
$\Lambda \mathrm{s}$ the population of Wuhan, China, returns to work, asymptomatic cases of severe acute respiratory syndrome coronavirus 2 (SARS-CoV-2) are being discovered among workers receiving health checkups for work resumption. Previous studies have shown that asymptomatic cases can be a public health threat and might lead to another outbreak $(1,2)$. However, little is known about the clinical characteristics of asymptomatic infections. We report on cases of asymptomatic SARS-CoV-2 infection among persons during work resumption screening in Wuhan.

At Wuhan Pingan Healthcare Diagnostic Center, we reviewed 29,299 asymptomatic persons who were screened for SARS-CoV-2 by reverse transcription PCR (RT-PCR) and 22,633 asymptomatic persons tested for SARS-CoV-2 antibodies during March 13-April 25, 2020. Throat swab specimens were tested for SARS-CoV-2 by using Real-Time FluorescentPCR Kits (DAAN GENE Co., LTD, https://www. en.daangene.com; Appendix, https://wwwnc.cdc. gov/EID/article/28/9/20-1848-App1.pdf). We used colloidal gold-based immunochromatographic strip assay, Novel Coronavirus (SARS-CoV-2) IgM/IgG Antibody Detection Assay (Vazyme Biotech Co. Ltd., http://vazyme.bioon.com.cn) to perform antibody testing (Appendix). We recorded the demographic features, exposure history, RT-PCR and serology results, and imaging reports at the time of testing. We obtained follow-up data from persons screened by telephone.

Among 29,299 persons screened by RT-PCR, we confirmed $18(0.061 \%)$ cases of SARS-CoV-2 infection. Of 22,633 persons tested for SARS-CoV-2 antibodies, $617(2.7 \%)$ cases had positive IgG but negative IgM; $196(0.87 \%)$ cases had positive IgG and IgM; and 40 $(0.18 \%)$ cases had negative IgG but positive IgM.

The median age of 18 asymptomatic case-patients (10 male, 8 female) was 30.5 years (Table). Six (33.3\%) cases had clear contact history with a confirmed case of SARS-CoV-2 infection. The median cycle threshold $\left(C_{t}\right)$ values on the day of first positive RT-PCR were $38.2\left(C_{t}\right.$ range 37.2-39.3) for ORFa1b gene and 38.1 ( $C_{t}$ range $\left.36.81-38.5\right)$ for $\mathrm{N}$ gene (Table). All antibody tests were obtained on the day of first positive RT-PCR except in 1 case (obtained 6 days later). Half $(7 / 14)$ the cases had negative IgM and IgG; the other half had positive IgG but negative IgM results (Table). Among 8 case-patients who had computed tomography imaging of the chest, none had remarkable findings. We closely observed the cases for 3-41 (median 16.5) days; 13 cases had negative RT-PCR within a median of 8 (range 3-14) days (Table), and none had symptoms. Among 41 close contacts, all had 2 consecutive negative RT-PCR tests $\geq 24$ hours apart. 